TP Periodica Polytechnica Electrical Engineering and Computer Science

59(4), pp. 138-146, 2015

DOI: 10.3311/PPee. 8438

Creative Commons Attribution (1)

RESEARCH ARTICLE

\section{A Redundancy Based Optimal Placement of Interline Power Flow Controller Using Composite Severity Index for Contingency Management}

\author{
Akanksha Mishra $^{1}$, G. V. Nagesh Kumar ${ }^{1 *}$
}

Received 26 July 2015; accepted after revision 13 November 2015

\begin{abstract}
Contingency assessment is an essential task for the stable and reliable operation of a power system as it predicts the effect of outages in transmission lines and generator units. In this paper, a recurrence of severity based placement strategy for Interline Power Flow Controller (IPFC) has been proposed. Contingency ranking of the lines has been done using Composite Severity Index. A probabilistic based strategy has been adopted for the placement of IPFC. IPFC is placed on the line which has the highest probability of severity during the occurrence for different outages. To verify the proposed methodology, it has been tested on IEEE 14 and 30 bus system. The load on the bus with highest load is further increased gradually up to the critical value and the results have been presented and analyzed to ascertain the effectiveness of IPFC for contingency management.
\end{abstract}

\section{Keywords}

Contingency, Interline Power Flow Controller, Line Utilization Factor, Fast Voltage Stability Index, Composite Severity Index, Optimal Placement

\footnotetext{
${ }^{1}$ Department of Electrical \& Electronics Engineering, GITAM Institute of Technology, GITAM University, Gandhi Nagar, Rushikonda, Visakhapatnam-530 045, Andhra Pradesh, India *Corresponding author, e-mail: drgvnk@rediffmail.com
}

\section{Introduction}

Around the world, the instances of blackout or total failure are ever-increasing. Secure operation of power system under both normal and contingency condition has become a very significant problem in today's complex electrical networks. In power system planning, contingency severity calculation is one of the most important aspects of power system reliability.

Several steady state and dynamic contingency ranking methods are used for contingency screening [1-6]. During system disturbances, system stability becomes vulnerable and there is a high risk of moving towards global instability or total collapse or blackout if preventive actions are not taken quickly. FACTS devices are preferred in modern power systems based on the requirement and are found to deliver good solution. Placement of FACTS devices at an appropriate location provides a good solution to blackout prevention [7-12]. Moazzami et al. [13] have presented a new approach for blackout prevention in a power system using parallel FACTS devices along with application of some corrective actions. Several metaheuristic methods have also been adopted for optimal placement of FACTS devices to improve the system conditions post contingency.

Security estimation of a power system under normal and contingency condition is a primary objective of power system engineers. Under contingency condition, voltage instability and line overload become a problem of major concern during operation of power systems. Therefore, in the system contingency ranking, it is necessary to consider voltage stability index along with line overload index for assessing the actual system stress under a contingency. IPFC is the most recent FACTS device, which is highly flexible and versatile. Since, IPFC consists of multiple VSC's with a common DC link, it has the capacity of compensating multiple transmission lines $[14,15]$. Optimal placement of IPFC for contingency management is an opportunity yet to be explored. Usually FACTS devices are placed on the most severe line to reduce the severity of the line. However, the most severe line may not have a very high probability of occurrence of severity. It is highly probable that some other line in the system may be endangered more frequently at the occurrence of various contingencies. It is assumed that the line with high probability 
of severity is more in need of a FACTS device for the improvement of the post-contingency condition of the system.

In this paper, an offline long term investment strategy for placement of IPFC is being proposed for protection of power system against contingency. The line which has the highest probability of severity is proposed to be the optimal location for IPFC placement. Two separate indices Line Utilization Factor and Fast Voltage Severity Index have been combined to form a Composite Severity Index (CSI) to evaluate line overloads and bus voltage violations. Line Utilization Factor (LUF) is employed for the measurement of line overloads in terms of both real and reactive power. Fast Voltage Stability Index (FVSI) has been used for voltage contingency ranking. Both indices have been combined to form a Composite Severity Index, which is used to obtain an accurate estimate of overall stress on the line. The IPFC is placed on the line which is repeated most frequently on the severity list of CSI for the various outages. The load on the highest loaded node is increased gradually up to the critical level. The proposed method is implemented and tested on an IEEE 14 and 30 bus system. The results have been presented and analyzed for illustration purposes.

\section{Mathematical Model of IPFC}

IPFC consists of at least two back to back DC-AC converters connected by a common DC link [16]. $\mathrm{V}_{\mathrm{i}}, \mathrm{V}_{\mathrm{j}}, \mathrm{V}_{\mathrm{k}}$ are complex voltages at bus i, j, k respectively. $V_{1}=V_{1}\left\llcorner\theta_{1}(1=i, j, k)\right.$ and $\mathrm{V}_{1}, \theta_{1}$ are the magnitude and angle of $\mathrm{V}_{1}$. $\mathrm{Vse}_{\text {in }}$ is the complex controllable, series injected voltage source. It shows the series compensation of the series converter. $\mathrm{Vse}_{\text {in }}$ is given by $\mathrm{Vse}_{\text {in }}$ $=\mathrm{Vse}_{\text {in }}\left\llcorner\theta \mathrm{se}_{\text {in }}(\mathrm{n}=\mathrm{j}, \mathrm{k}) . \mathrm{Vse}_{\text {in }}\right.$ and $\theta \mathrm{se}_{\text {in }}$ are the magnitude and angle of Vsein.

The basic model of IPFC consists of three buses $\mathrm{i}, \mathrm{j}$ and $\mathrm{k}$. Two transmission lines are connected with the bus $i$ in common. The equivalent circuit of the IPFC with two converters is represented in Fig. 1. $Z_{\text {sein }}$ is the series transformer impedance. $\mathrm{P}_{\text {sein }}$ is the active power exchange of each converter via the common DC link. $\mathrm{P}_{\mathrm{i}}$ and, $\mathrm{Q}_{\mathrm{i}}$ as given in Eqs. (1) and (2) are the sum of the active and reactive power flows leaving the bus i. The IPFC branch active and reactive power flows leaving bus $n$ are $P_{n i}$ and $Q_{n i}$ and the expressions are given in Eqs. (3) and (4). $\mathrm{I}_{\mathrm{ji}}, \mathrm{I}_{\mathrm{ki}}$ are the IPFC branch currents of branch $\mathrm{j}$ - $\mathrm{i}$ and $\mathrm{k}-\mathrm{i}$ leaving bus $\mathrm{j}$ and $\mathrm{k}$, respectively.

$$
\begin{gathered}
P_{i}=V_{i}^{2} g_{i i}-\sum_{n} V_{i} V_{n}\left[g_{i n} \cos \left(\theta_{i}-\theta_{n}\right)+b_{i n} \sin \left(\theta_{i}-\theta_{n}\right)\right] \\
-\sum_{n} V_{i} V s e_{i n}\left[g_{i n} \cos \left(\theta_{i}-\theta s e_{i n}\right)-b_{i n} \sin \left(\theta_{i}-\theta s e_{i n}\right)\right] \\
Q_{i}=-V_{i}^{2} b_{i i}-\sum_{n=j, k} V_{i} V_{n}\left[g_{i n} \sin \left(\theta_{i}-\theta_{n}\right)-b_{i n} \cos \left(\theta_{i}-\theta_{n)}\right)\right] \\
-\sum_{n=j, k} V_{i} V s e_{i n}\left[g_{i n} \sin \left(\theta_{i}-\theta s e_{i n}\right)-b_{i n} \cos \left(\theta_{i}-\theta s e_{i n}\right)\right]
\end{gathered}
$$

$$
\begin{aligned}
& P_{n i}=V_{n}^{2} g_{n n}-V_{i} V_{n}\left[g_{i n} \cos \left(\theta_{n}-\theta_{i}\right)+b_{i n} \sin \left(\theta_{n}-\theta_{i}\right)\right] \\
& +V_{n} V s e_{i n}\left[g_{i n} \sin \left(\theta_{n}-\theta s e_{i n}\right)-b_{i n} \cos \left(\theta_{n}-\theta s e_{i n}\right)\right] \\
& Q_{n i}=-V_{n}^{2} b_{n n}-V_{i} V_{n}\left[g_{i n} \sin \left(\theta_{n}-\theta_{i}\right)-b_{i n} \cos \left(\theta_{n}-\theta_{i}\right)\right] \\
& +V_{n} V s e_{i n}\left[g_{i n} \sin \left(\theta_{n}-\theta s e_{i n}\right)-b_{i n} \cos \left(\theta_{n}-\theta s e_{i n}\right)\right]
\end{aligned}
$$

Where $n=j, k$

$$
\begin{aligned}
& g_{\text {in }}+j b_{i n}=1 / z s e_{i n}=y s e_{i n}, g_{n n}+j b_{n n}=1 / z s e_{i n}=y s e_{i n} \\
& g_{i i}=\sum_{n=j, k} g_{i n}, b_{i i}=\sum_{n=j, k} b_{i n}
\end{aligned}
$$

Assuming lossless converter, the active power supplied by one converter equals the active power demanded by the other, if there are no underlying storage systems.

$$
\operatorname{Re}\left(V s e_{i j} I_{j i}^{*}+V s e_{i k} I_{k i}^{*}\right)=0
$$

Where, the superscript $*$ denotes the complex conjugate.

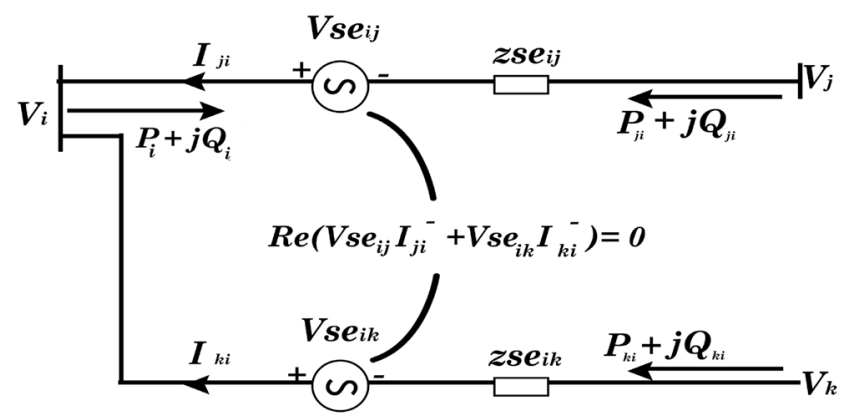

Fig. 1 Equivalent circuit of IPFC

\section{Composite Severity Index}

\subsection{Line Utilization Factor}

Line Utilization Factor is an index used for determining the severity of the system loading under normal and contingency condition. It is given by Eq. (6)

$$
L U F_{i j}=\frac{M V A_{i j}}{M V A_{i j \max }}
$$

where, $\mathrm{LUF}_{\mathrm{ij}}$ is Line utilization factor (LUF) of the line connected to bus i and bus j. $\mathrm{MVA}_{\mathrm{ij}(\max )}$ is Maximum MVA rating of the line between bus $i$ and bus $j$ and MVA $_{i j}$ is actual MVA rating of the line between bus $i$ and bus $j$.

LUF will be small when the line under consideration carries an apparent within its limits and reaches a high value during overloads. Thus, it provides a precise measure of severity of the line overloads for a given state of the power system. When LUF $\geq 1$, the line is considered to be overloaded. The overall LUF of the system is the sum of LUF's of all lines and is given by

$$
\text { OverallLUF }=\sum_{\forall L} L U F
$$

Where, $\mathrm{L}$ is the no. of lines in the system. 


\subsection{Fast Voltage Stability Index (FVSI)}

Fast Voltage Stability Index (FVSI) is a line-based voltage stability indicator given by Eq. (8)

$$
F V S I_{i j}=\frac{4 Z^{2} Q_{j}}{V_{i}^{2} X}
$$

where, $\mathrm{Z}$ is the line impedance, $\mathrm{X}$ is the line reactance, $\mathrm{Q}_{\mathrm{j}}$ is the reactive power at bus $\mathrm{j}$ and $\mathrm{V}_{\mathrm{i}}$ is the voltage magnitude at bus $i$. FVSI is used to indicate a stable operating region of the load. A line with FVSI value nearer to zero is considered to be a healthy line pertaining to stability. Higher the value of FVSI of a line, weaker is the line with respect to stability, i.e. closer it is considered towards instability. A system is considered to be unstable if FVSI $\geq 1$. The overall FVSI of the system is given by

$$
\text { OverallFVSI }=\sum_{\forall L} F V S I
$$

\subsection{Composite Severity Index (CSI)}

After obtaining the LUF and FVSI values of all the lines for a particular line outage, the composite severity index is calculated as given in Eq. (10)

$$
C I_{i j}=w_{1} \times L U F_{i j}+w_{2} \times F V S I_{i j}
$$

where, $\mathrm{w}_{1}$ and $\mathrm{w}_{2}$ are the weighting factors of the two indices for line $i-j$. The sum of $w_{1}$ and $w_{2}$ is equal to unity. The weighting factors may be used to reflect the relative importance of the indices. In this study, the equal weightage has been given to both the indices. The overall CSI of the system is given by

$$
\text { OverallCSI }_{i}=\sum_{\forall L} C S I
$$

\section{Results and Discussions \\ 4.1 IEEE 14 Bus Test System}

An IEEE 14 bus test system has 4 generator buses, 9 load buses and 20 transmission lines as seen in Fig. 2. Bus 1 is the slack bus. Bus number 2, 3, 6, 8 are the generator buses. The remaining buses are load bus. Only load buses have been considered for IPFC placement.

First, the most severe line corresponding to every outage is identified and tabulated down along with the details of the indices values in Table 1, in descending order of CSI. An IPFC with two converters is chosen for the study. Only lines connected between load buses have been considered for IPFC placement.

A pie chart showing the regularity of severity in different lines after the contingency analysis of the system has been presented in Fig. 3. It is observed from the chart that for different outages the line connected between the buses 9-14 is most prone to severity in comparison to other lines. Hence the line 9-14 is chosen for the placement of 1 st converter of the IPFC. The Line 9-14 has highest severity when outage of line 13-14 occurs. Hence further analysis is carried out for line 13-14 contingency.
Three lines have been connected with the line 9-14 through a common bus. The CSI values of these lines for line 13-14 outage have been given in Table 2. It is observed that line connected between buses 9-10 has the least CSI value, hence is the healthiest line. Hence the second converter of IPFC is chosen to be placed on line 9-10.Thus further analysis is done for line 13-14 contingency with IPFC placement at 9-14 and 9-10.

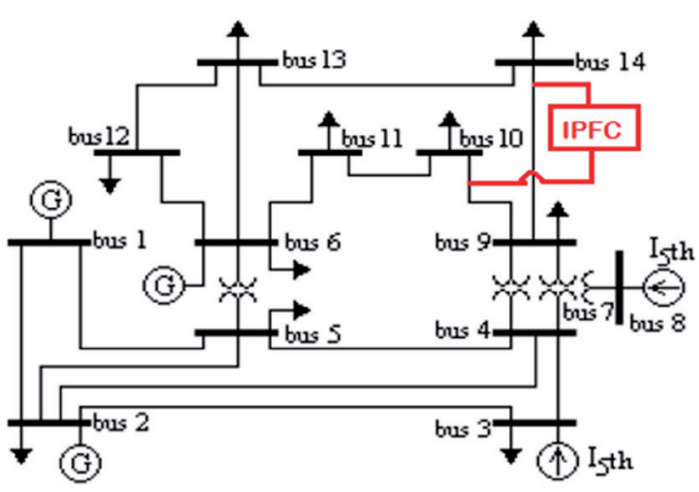

Fig. 2 IEEE 14 Bus Test System with IPFC installed at line connected between buses 9-14 and 9-10

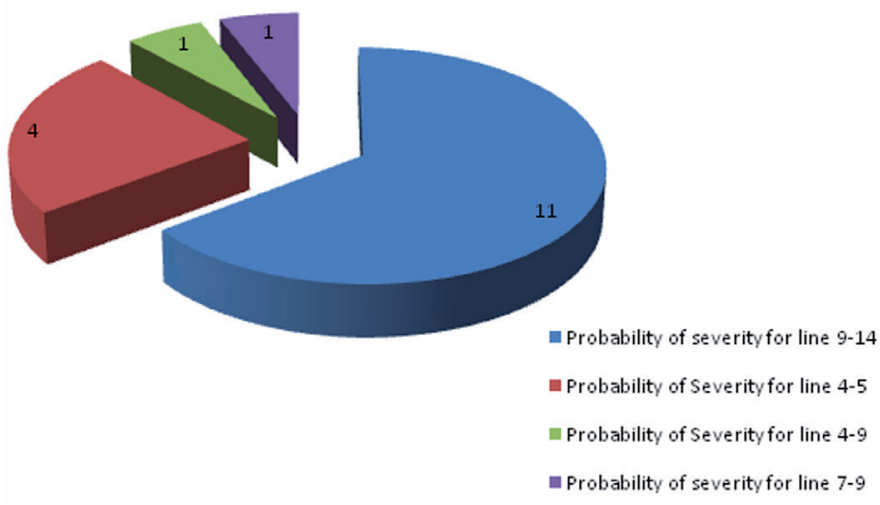

Fig. 3 Probability of Severity of Various Lines for line outages of 14 Bus Test System

Various parameters of the system are studied for three different system conditions - without contingency, with contingency at line 13-14 and with optimal placement of IPFC. The results have been tabulated in Table 3. The parameters taken into consideration are active power loss, reactive power loss, Overall FVSI, Overall CSI, Overall LUF, FVSI, LUF, and CSI of line 9-14. The active and reactive power loss of the healthy system (without contingency) is found to be 22.5451 MW and 82.1714 MVAR respectively. With the outage of line 13-14, it is observed that the active and reactive power loss of the system is increased to $29.2832 \mathrm{MW}$ and 109.3464 MVAR. After placement of IPFC in the line 9-14 and 9-10, the active and reactive power loss of the system reduced to 22.266 MW and 74.518 MVAR respectively. It is observed that contingency in line 13-14 increases the severity of the line 9-14 as given by FVSI and CSI values. Placement of IPFC at the proposed location reduces the value of the indices to pre-contingency state. The overall LUF, FVSI and CSI of the system also improve with placement of IPFC at the proposed location. 
Table 1 LUF, FVSI and CSI values of most severe line for various line outage by Contingency Analysis For IEEE 14 Bus Test System

\begin{tabular}{|c|c|c|c|c|c|c|c|c|c|c|}
\hline \multicolumn{2}{|c|}{ Line Outage } & \multicolumn{2}{|c|}{ Severe line } & \multirow{2}{*}{ LUF (p.u.) } & \multicolumn{2}{|c|}{ Severe Line } & \multirow{2}{*}{ FVSI (p.u.) } & \multicolumn{2}{|c|}{ Severe line } & \multirow{2}{*}{ CSI (p.u.) } \\
\hline $\mathrm{FB}$ & $\mathrm{TB}$ & $\mathrm{FB}$ & TB & & FB & $\mathrm{TB}$ & & FB & TB & \\
\hline 13 & 14 & 9 & 14 & 0.747 & 9 & 14 & 1.243 & 9 & 14 & 0.9954 \\
\hline 1 & 2 & 4 & 5 & 1.399 & 9 & 14 & 0.513 & 4 & 5 & 0.7398 \\
\hline 7 & 9 & 4 & 5 & 0.429 & 13 & 14 & 0.736 & 4 & 9 & 0.5675 \\
\hline 5 & 6 & 4 & 5 & 1.064 & 13 & 14 & 0.688 & 4 & 5 & 0.5429 \\
\hline 2 & 3 & 4 & 5 & 1.007 & 9 & 14 & 0.516 & 4 & 5 & 0.5108 \\
\hline 6 & 12 & 4 & 5 & 0.599 & 9 & 14 & 0.591 & 9 & 14 & 0.4974 \\
\hline 2 & 4 & 4 & 5 & 0.960 & 9 & 14 & 0.513 & 4 & 5 & 0.4953 \\
\hline 6 & 11 & 7 & 9 & 0.654 & 13 & 14 & 0.562 & 7 & 9 & 0.467 \\
\hline 12 & 13 & 4 & 5 & 0.597 & 9 & 14 & 0.551 & 9 & 14 & 0.4645 \\
\hline 4 & 7 & 4 & 5 & 0.480 & 9 & 14 & 0.546 & 9 & 14 & 0.451 \\
\hline 4 & 5 & 7 & 9 & 0.456 & 9 & 14 & 0.536 & 9 & 14 & 0.4391 \\
\hline 3 & 4 & 4 & 5 & 0.519 & 9 & 14 & 0.512 & 9 & 14 & 0.4323 \\
\hline 4 & 9 & 7 & 9 & 0.603 & 9 & 14 & 0.520 & 9 & 14 & 0.431 \\
\hline 2 & 5 & 7 & 9 & 0.484 & 9 & 14 & 0.508 & 9 & 14 & 0.4286 \\
\hline 10 & 11 & 4 & 5 & 0.630 & 9 & 14 & 0.514 & 9 & 14 & 0.4234 \\
\hline 9 & 10 & 4 & 5 & 0.570 & 9 & 14 & 0.501 & 9 & 14 & 0.4219 \\
\hline 1 & 5 & 7 & 9 & 0.481 & 9 & 14 & 0.502 & 9 & 14 & 0.4211 \\
\hline
\end{tabular}

FB- From Bus, TB- To Bus

Table 2 LUF OF Lines Connected to Line 9-14 for 13-14 Contingency

\begin{tabular}{cccc}
\hline S. No. & From Bus & To Bus & CSI (p.u.) \\
\hline 1. & 9 & 10 & 0.1104 \\
2. & 9 & 4 & 0.3481 \\
3. & 9 & 7 & 0.5264 \\
\hline
\end{tabular}

Table 3 Comparison of results without Contingency, with contingency and with optimal placement Of IPFC at 9-14 and 9-10

\begin{tabular}{lccc}
\hline & \multicolumn{3}{c}{ Values in different system state } \\
\cline { 2 - 4 } Parameter & Without & With Contingency & With optimal \\
& contingency & At 13-14 & placement of IPFC \\
\hline Active Power Loss (MW) & 22.5451 & 29.2832 & 22.266 \\
Reactive Power Loss (MVAR) & 82.1714 & 109.3464 & 74.518 \\
LUF of Severe Line (p.u.) & 0.3556 & 0.7479 & 0.6406 \\
FVSI of Severe Line (p.u.) & 0.5162 & 1.243 & 0.7539 \\
CSI of Severe Line (p.u.) & 0.4359 & 0.9954 & 0.6973 \\
Voltage Deviation (p.u.) & 0.6961 & 1.0793 & 0.6024 \\
Overall LUF (p.u.) & 9.2219 & 10.1456 & 8.7642 \\
Overall FVSI (p.u.) & 3.6661 & 4.7349 & 3.0421 \\
Overall CSI (p.u.) & 5.9146 & 7.4403 & 5.9031 \\
\hline
\end{tabular}


Bus 4 is the highest loaded bus of the system under consideration. Load at bus 4 is further increased gradually up to the critical level ( $\mathrm{P}=109.8 \mathrm{MW}, \mathrm{Q}=87.9 \mathrm{MVAR})$ and the results have been presented in Table 4 . The load flow program did not converge for any further increase in load beyond this limit. A sample of some most congested lines is taken. The CSI values of these lines for different loadings have been tabulated. From Table 4 it is clear that line 9-14 ranks highest in congestion for all different loadings. With placement of IPFC, the congestion in the line gets reduced to a good extent. The CSI values for line 9-14 for different loads for all the three system conditions have been shown graphically in Fig. 4. The voltage profile of the 14 bus system has been given in Fig. 5. It shows a very good improvement in the voltage of the buses with placement of IPFC at the proposed location.

Table 4 Indices Of Severe Lines under Increased Loading Conditions

\begin{tabular}{|c|c|c|c|c|}
\hline $\begin{array}{l}\text { Loading at } \\
\text { node } 4\end{array}$ & Line No & $\begin{array}{c}\text { CSI w/t } \\
\text { contingency } \\
\text { (p.u.) }\end{array}$ & $\begin{array}{c}\text { CSI with } \\
\text { Contingency } \\
\text { (p.u.) }\end{array}$ & $\begin{array}{l}\text { CSI with Opt. } \\
\text { IPFC (p.u.) }\end{array}$ \\
\hline $\mathrm{P}=47.8$ & $9-14$ & 0.4359 & 0.9954 & 0.6973 \\
\hline MW & $1-5$ & 0.4829 & 0.5250 & 0.4393 \\
\hline $\begin{array}{l}\mathrm{Q}=30.9 \\
\text { MVAR }\end{array}$ & $4-5$ & 0.3101 & 0.3525 & 0.4438 \\
\hline (Normal & $2-4$ & 0.3590 & 0.3899 & 0.3766 \\
\hline Load) & $2-3$ & 0.4047 & 0.4115 & 0.4110 \\
\hline & $9-14$ & 0.4253 & 1.0710 & 0.7345 \\
\hline $\mathrm{P}=70.8$ & $1-5$ & 0.5706 & 0.6219 & 0.5044 \\
\hline $\begin{array}{l}\text { MW } \\
Q=60.9\end{array}$ & $4-5$ & 0.3962 & 0.4489 & 0.5139 \\
\hline \multirow[t]{2}{*}{ MVAR } & $2-4$ & 0.4377 & 0.4792 & 0.4528 \\
\hline & $2-3$ & 0.4468 & 0.4558 & 0.4336 \\
\hline $\mathrm{P}=109.8$ & $9-14$ & 0.4124 & 1.25 & 0.7689 \\
\hline MW & $1-5$ & 0.7109 & 0.7632 & 0.6021 \\
\hline $\begin{array}{l}\mathrm{Q}=87.9 \\
\text { MVAR }\end{array}$ & $4-5$ & 0.5161 & 0.5744 & 0.6146 \\
\hline (Critical & $2-4$ & 0.5302 & 0.6041 & 0.5555 \\
\hline Load) & $2-3$ & 0.4823 & 0.4973 & 0.47 \\
\hline
\end{tabular}

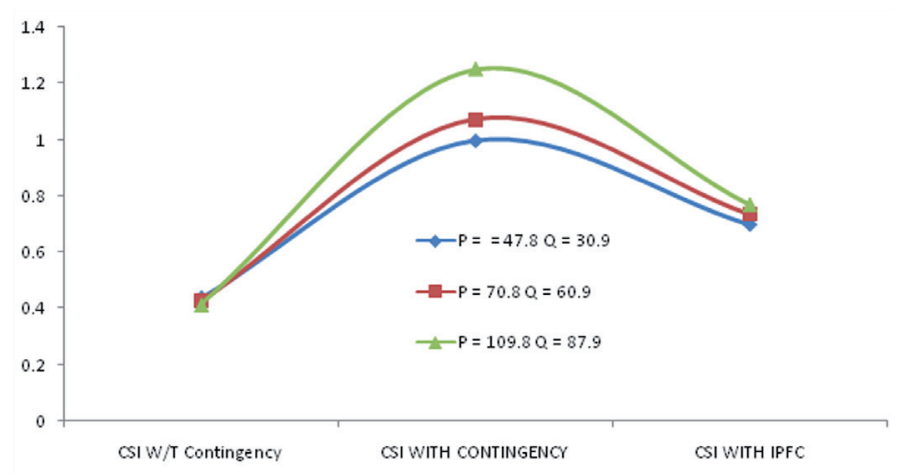

Fig. 4 CSI of line 24-25 at different loads without Contingency, with contingency and with IPFC

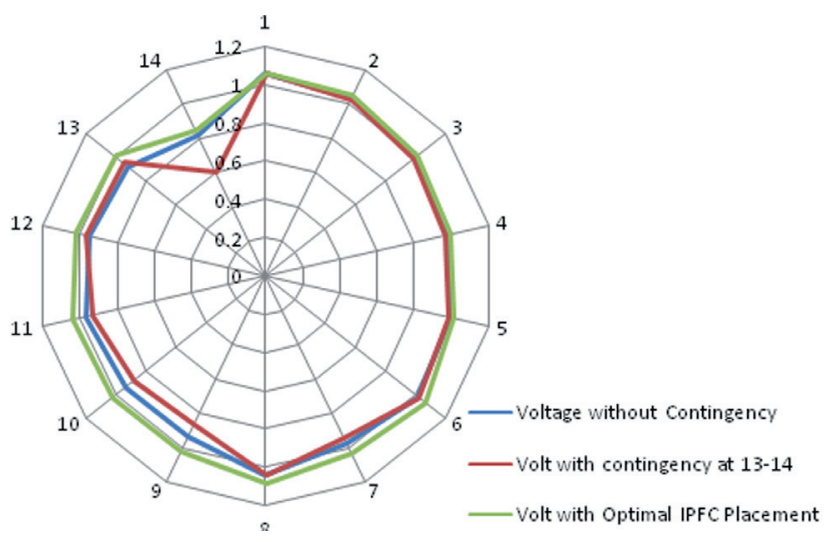

Fig. 5 Comparison of Voltage Profile without contingency, with contingency, and with optimal placement of IPFC under normal loading

\subsection{IEEE 30 Bus Test System}

An IEEE 30 bus system is considered, in which bus no. 1 is considered as a slack bus and bus nos. 2, 5, 8, 11, 13 are considered as PV buses while all other buses are load bus as shown in Fig. 6. This system has 41 connected lines. The details of the severe lines for each outage with respect to LUF, FVSI and CSI have been given in Table 5, in descending order of CSI. The probability of severity of different lines has been shown in Fig. 7. It is observed that line 9-10 is the most frequently repeated severe line (in terms of CSI) for various contingencies. Hence, line connected between buses 9-10 is chosen for the placement of the $1^{\text {st }}$ converter of IPFC. The maximum value of CSI for line 9-10 is 0.5577 p.u. when there is an outage of line 12-15 from Table 5. Hence, further analysis is carried out for line 12-15 contingency.

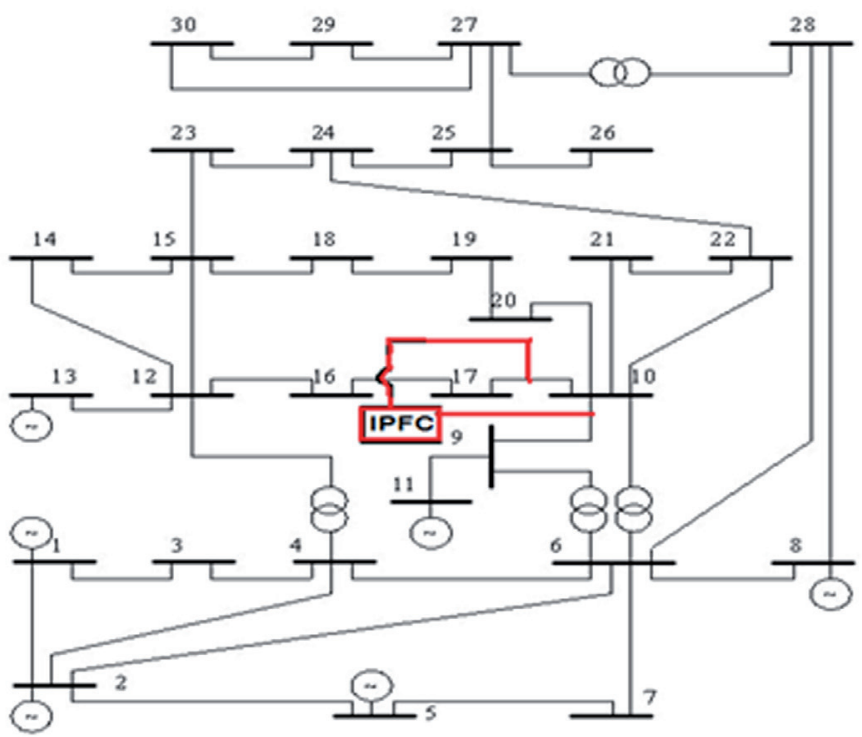

Fig. 6 IEEE 30 Bus Test System with IPFC installed at line connected between buses $9-10$ and 10-17 
Table 5 LUF, FVSI and CSI values of most severe line for various line outage by Contingency Ranking for IEEE 30 bus Test System

\begin{tabular}{|c|c|c|c|c|c|c|c|c|c|c|}
\hline \multicolumn{2}{|c|}{ Line Outage } & \multicolumn{2}{|c|}{ Severe line } & \multirow{2}{*}{ LUF (p.u.) } & \multicolumn{2}{|c|}{ Severe Line } & \multirow{2}{*}{ FVSI (p.u.) } & \multicolumn{2}{|c|}{ Severe line } & \multirow{2}{*}{ CSI (p.u. } \\
\hline FB & TB & FB & TB & & FB & TB & & FB & $\mathrm{TB}$ & \\
\hline 12 & 15 & 3 & 4 & 0.8477 & 6 & 10 & 0.5438 & 9 & 10 & 0.5577 \\
\hline 6 & 10 & 3 & 4 & 0.8449 & 28 & 27 & 0.4177 & 9 & 10 & 0.5566 \\
\hline 6 & 9 & 3 & 4 & 0.8495 & 6 & 10 & 0.5565 & 6 & 10 & 0.5565 \\
\hline 12 & 16 & 3 & 4 & 0.8417 & 6 & 10 & 0.5115 & 9 & 10 & 0.5323 \\
\hline 2 & 4 & 3 & 4 & 1.0023 & 6 & 10 & 0.4111 & 3 & 4 & 0.5114 \\
\hline 15 & 18 & 3 & 4 & 0.8427 & 6 & 10 & 0.4708 & 9 & 10 & 0.5019 \\
\hline 4 & 6 & 4 & 12 & 0.7072 & 6 & 10 & 0.4215 & 4 & 12 & 0.4938 \\
\hline 25 & 27 & 3 & 4 & 0.8417 & 6 & 10 & 0.45 & 9 & 10 & 0.4872 \\
\hline 16 & 17 & 3 & 4 & 0.8386 & 6 & 10 & 0.4501 & 9 & 10 & 0.486 \\
\hline 12 & 14 & 3 & 4 & 0.8432 & 6 & 10 & 0.4426 & 9 & 10 & 0.4807 \\
\hline 15 & 23 & 3 & 4 & 0.8384 & 6 & 10 & 0.4423 & 9 & 10 & 0.4803 \\
\hline 6 & 28 & 3 & 4 & 0.8431 & 6 & 10 & 0.4288 & 9 & 10 & 0.4757 \\
\hline 1 & 3 & 9 & 10 & 0.6526 & 6 & 10 & 0.4063 & 9 & 10 & 0.4752 \\
\hline 3 & 4 & 9 & 10 & 0.6503 & 6 & 10 & 0.4063 & 9 & 10 & 0.473 \\
\hline 24 & 25 & 3 & 4 & 0.8398 & 6 & 10 & 0.429 & 9 & 10 & 0.4703 \\
\hline 18 & 19 & 3 & 4 & 0.8387 & 6 & 10 & 0.4233 & 9 & 10 & 0.4661 \\
\hline 27 & 30 & 3 & 4 & 0.8444 & 27 & 29 & 0.4884 & 9 & 10 & 0.4648 \\
\hline 6 & 8 & 3 & 4 & 0.8442 & 6 & 10 & 0.4081 & 9 & 10 & 0.4637 \\
\hline 14 & 15 & 3 & 4 & 0.8391 & 6 & 10 & 0.4203 & 9 & 10 & 0.4633 \\
\hline 8 & 28 & 3 & 4 & 0.8397 & 6 & 10 & 0.4165 & 9 & 10 & 0.4627 \\
\hline 5 & 7 & 3 & 4 & 0.8086 & 6 & 10 & 0.4122 & 9 & 10 & 0.4613 \\
\hline 29 & 30 & 3 & 4 & 0.84 & 6 & 10 & 0.4172 & 9 & 10 & 0.4611 \\
\hline 23 & 24 & 3 & 4 & 0.8391 & 6 & 10 & 0.4156 & 9 & 10 & 0.4597 \\
\hline 6 & 7 & 3 & 4 & 0.7573 & 6 & 10 & 0.4232 & 9 & 10 & 0.4577 \\
\hline 10 & 22 & 3 & 4 & 0.8399 & 28 & 27 & 0.4195 & 9 & 10 & 0.4527 \\
\hline 22 & 24 & 3 & 4 & 0.8399 & 28 & 27 & 0.4195 & 9 & 10 & 0.4527 \\
\hline 19 & 20 & 3 & 4 & 0.8418 & 6 & 10 & 0.4047 & 9 & 10 & 0.4509 \\
\hline 10 & 20 & 3 & 4 & 0.85 & 15 & 18 & 0.462 & 9 & 10 & 0.438 \\
\hline 10 & 21 & 3 & 4 & 0.8488 & 28 & 27 & 0.4344 & 3 & 4 & 0.433 \\
\hline 10 & 17 & 3 & 4 & 0.8433 & 28 & 27 & 0.3726 & 3 & 4 & 0.4302 \\
\hline 21 & 23 & 3 & 4 & 0.8396 & 6 & 10 & 0.4026 & 6 & 10 & 0.4026 \\
\hline
\end{tabular}


Line 9-10 is connected to line 6-9, 6-10, 9-11, 10-20, 10-17, 10-21, and 10-22 through a common bus. The CSI values of these lines have been presented in Table 6. It is observed that line 10-17 is the healthiest line in terms of CSI. Therefore, this is the location chosen for the placement of $2^{\text {nd }}$ converter of IPFC. Hence further analysis is carried out for line 12-15 outage and IPFC placement on line 9-10 and 10-17.

Table 6 CSI values of lines connected to line 9-10

\begin{tabular}{cccc}
\hline S. No. & From Bus & To Bus & CSI (p.u.) \\
\hline 1 & 6 & 9 & 0.2801 \\
2 & 6 & 10 & 0.4125 \\
3 & 9 & 11 & 0.5042 \\
4 & 10 & 20 & 0.2714 \\
5 & 10 & 17 & 0.0343 \\
6 & 10 & 21 & 0.2602 \\
7 & 10 & 22 & 0.0676 \\
\hline
\end{tabular}

The load flow solution was run with IPFC for 30 bus system and the results obtained are given in Table 7. It is observed from Table 7, the active and reactive power loss of the healthy system was 22.288 MW and 102.33 MVAR respectively. With outage of line 12-15 the losses increased to $32.8249 \mathrm{MW}$ and 139.3543 MVAR. When IPFC was placed on line 9-10 and 10-17 the active and reactive power losses reduced to $19.8 \mathrm{MW}$ and 66.823 MVAR. It can also be observed that voltage deviation; overall LUF, FVSI and CSI of the system have been improved to the healthy state (without contingency condition) with the optimal placement of IPFC. The LUF, FVSI, and CSI values of line 9-10 have also been mentioned under the different system conditions, namely, without Contingency, With Contingency at 12-15, with IPFC at 9-10 and 10-17. A reduction in the value of the indices has been observed after the placement of IPFC at the proposed location. CSI of line 9-10 increased from 9.1741 p.u. to 10.9321 p.u. after contingency. When IPFC was placed, the CSI value of line 9-10 reduced to 7.2486 p.u.

Bus 7 is the load bus with the highest load. Loading at node 7 is increased gradually up to the critical level, and the system response as referred to severe lines has been studied and presented in Table 8. The load was increased up to a level $\mathrm{P}=$ 299.8 MW and Q = 258.2 MVAR respectively. If any further active or reactive load was added, it was observed that the load flow solution did not converge. Hence, $\mathrm{P}=299.8 \mathrm{MW}$ and $\mathrm{Q}=$ 258.2 MVAR is the critical load at bus 7. The results show that LUF, FVSI and CSI values of all severe lines have decreased after the placement of IPFC. Out of these lines, line 9-10 is the location for IPFC placement. Figure 8 shows the decrease in severity of line 9-10 with respect to LUF, FVSI and CSI values after the placement of IPFC. The bus voltages of the 30 bus system, under normal loading have been plotted in Fig. 9. It is observed that after the placement of IPFC, the voltage of all the buses have improved and the values are nearly equal to unity.

Table 7 Comparison Without Contingency, With Contingency and With Optimal Placement of IPFC at 9-10 and 10-17 for Normal Loading

\begin{tabular}{lccc}
\hline Parameter & $\begin{array}{c}\text { Without } \\
\text { contingency }\end{array}$ & $\begin{array}{c}\text { With } \\
\text { Contingency }\end{array}$ & $\begin{array}{c}\text { With Placement } \\
\text { of IPFC }\end{array}$ \\
\hline $\begin{array}{l}\text { Active Power Loss } \\
\text { (MW) }\end{array}$ & 22.288 & 32.8249 & 19.8 \\
Reactive Power Loss & 102.33 & 139.3543 & 66.823 \\
(MVAR) & 3.1435 & 4.0856 & 0.9085 \\
Voltage Dev. (p.u.) & 0.6385 & 0.762 & 0.241 \\
LUF of sev. line (p.u.) & 0.2922 & 0.3699 & 0.0512 \\
FVSI of sev. Line (p.u.) & 0.4654 & 0.5661 & 0.1460 \\
CSI of Sev. Line (p.u.) & 12.962 & 15.1773 & 11.4397 \\
Overall LUF (p.u.) & 5.3858 & 4.0856 & 3.0574 \\
Overall FVSI (p.u.) & 9.1741 & 10.9321 & 7.2486 \\
\hline Overall CSI (p.u.) & & & \\
\hline
\end{tabular}

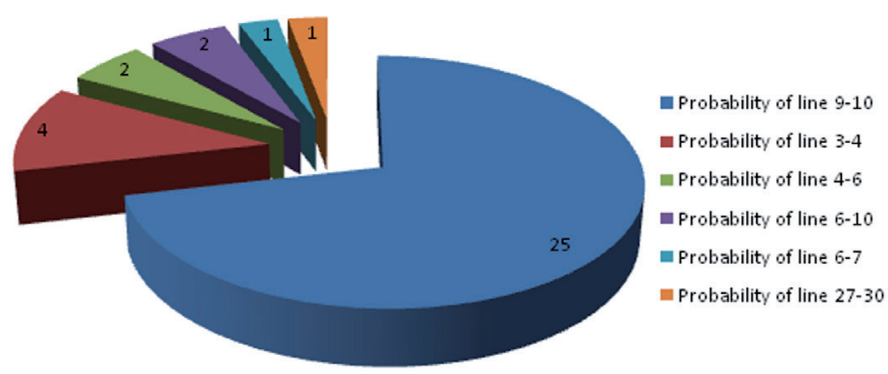

Fig. 7 Probability of Severity of various lines for line outages of 30 Bus Test System

\section{Conclusion}

IPFC can be very effective in either evading or at least reducing the severity of the system failure to a great extent. Proper placement of the costly device is necessary for its effective utilization.

- An approach for contingency estimation on the basis of probability of severity has been proposed.

- A composite index method has been used for the identification of severity of the system. The composite index is a combination of LUF and FVSI. Hence, CSI has the ability to predict the overall severity of the line. The severe lines for different line outages are identified and ranked in descending order of CSI for both test systems..

- The $1^{\text {st }}$ converter of IPFC is chosen to be placed on the line with highest probability of severity. The $2^{\text {nd }}$ converter is placed on the healthiest line that has a bus in common with the chosen line. It has been established that placement of IPFC effectively reduces line overload, 
Table 8 Analysis of some Severe lines with respect to LUF, FVSI and CSI values for increased loading

\begin{tabular}{|c|c|c|c|c|c|c|c|c|c|c|}
\hline $\begin{array}{l}\text { Loading } \\
\text { at node } \\
7\end{array}$ & $\begin{array}{l}\text { Line } \\
\text { No }\end{array}$ & $\begin{array}{l}\text { LUF without } \\
\text { contingency } \\
\text { (p.u.) }\end{array}$ & $\begin{array}{c}\text { LUF } \\
\text { with } \\
\text { Contingency } \\
\text { (p.u.) }\end{array}$ & $\begin{array}{c}\text { LUF } \\
\text { With IPFC } \\
\text { (p.u.) }\end{array}$ & $\begin{array}{c}\text { FVSI } \\
\text { without } \\
\text { contingency } \\
\text { (p.u.) }\end{array}$ & $\begin{array}{l}\text { FVSI with } \\
\text { Contingency } \\
\text { (p.u.) }\end{array}$ & $\begin{array}{l}\text { FVSI with } \\
\text { IPFC (p.u.) }\end{array}$ & $\begin{array}{c}\text { CSI without } \\
\text { contingency } \\
\text { (p.u.) }\end{array}$ & $\begin{array}{l}\text { CSI with } \\
\text { Contingency } \\
\text { (p.u.) }\end{array}$ & $\begin{array}{l}\text { CSI with } \\
\text { IPFC } \\
\text { (p.u.) }\end{array}$ \\
\hline \multirow{6}{*}{$\begin{array}{l}\mathrm{P}=22.8 \\
\mathrm{MW} \\
\mathrm{Q}= \\
10.9 \\
\text { MVAR }\end{array}$} & $9-10$ & 0.636 & 0.7562 & 0.2407 & 0.2849 & 0.3592 & 0.0512 & 0.4604 & 0.5577 & 0.146 \\
\hline & $3-4$ & 0.8392 & 0.8477 & 0.8431 & 0.0167 & 0.0164 & 0.0064 & 0.4279 & 0.4321 & 0.4247 \\
\hline & $6-10$ & 0.2342 & 0.2811 & 0.1582 & 0.4165 & 0.5438 & 0.2275 & 0.3253 & 0.4125 & 0.1929 \\
\hline & $28-27$ & 0.2969 & 0.3319 & 0.0871 & 0.3861 & 0.448 & 0.1091 & 0.3415 & 0.39 & 0.0981 \\
\hline & $4-6$ & 0.7216 & 0.7463 & 0.3905 & 0.0151 & 0.0057 & 0.0696 & 0.3683 & 0.376 & 0.2301 \\
\hline & $12-14$ & 0.159 & 0.3308 & 0.1342 & 0.1979 & 0.3764 & 0.1624 & 0.1785 & 0.3536 & 0.1483 \\
\hline \multirow{6}{*}{$\begin{array}{l}\mathrm{P}= \\
199.8 \\
\mathrm{MW} \\
\mathrm{Q}= \\
158.2 \\
\text { MVAR }\end{array}$} & $9-10$ & 0.6453 & 0.7818 & 0.6638 & 0.3185 & 0.4097 & 0.2733 & 0.4819 & 0.5957 & 0.4685 \\
\hline & $3-4$ & 1.4868 & 1.4997 & 1.5513 & 0.0043 & 0.0038 & 0.0342 & 0.7456 & 0.7518 & 0.7927 \\
\hline & $6-10$ & 0.1927 & 0.2439 & 0.2249 & 0.3615 & 0.5192 & 0.3138 & 0.2771 & 0.3815 & 0.2693 \\
\hline & $28-27$ & 0.286 & 0.3262 & 0.2223 & 0.4192 & 0.4968 & 0.3575 & 0.3526 & 0.4115 & 0.2899 \\
\hline & $4-6$ & 1.5535 & 1.5876 & 0.6475 & 0.032 & 0.0211 & 0.0437 & 0.7928 & 0.8044 & 0.3456 \\
\hline & $12-14$ & 0.1669 & 0.3584 & 0.3102 & 0.2148 & 0.4183 & 0.408 & 0.1909 & 0.3884 & 0.3591 \\
\hline $\mathrm{P}=$ & $9-10$ & 0.6602 & 0.8223 & 0.5096 & 0.3645 & 0.4928 & 0.1338 & 0.5124 & 0.6576 & 0.3217 \\
\hline $\begin{array}{l}299.8 \\
\text { MW }\end{array}$ & $3-4$ & 2.0646 & 2.1276 & 2.0021 & 0.0177 & 0.0201 & 0.0688 & 1.0412 & 1.0739 & 1.0354 \\
\hline $\mathrm{Q}=$ & $6-10$ & 0.1524 & 0.2042 & 0.2294 & 0.2882 & 0.4936 & 0.2294 & 0.2203 & 0.3489 & 0.1199 \\
\hline 258.2 & $28-27$ & 0.2784 & 0.3268 & 0.1677 & 0.473 & 0.59 & 0.289 & 0.3757 & 0.4584 & 0.2283 \\
\hline Critical & $4-6$ & 2.2524 & 2.347 & 1.0936 & 0.0273 & 0.0117 & 0.01 & 1.1398 & 1.1793 & 0.5518 \\
\hline Load & $12-14$ & 0.1764 & 0.3973 & 0.2582 & 0.2394 & 0.4922 & 0.2582 & 0.2079 & 0.4447 & 0.2981 \\
\hline
\end{tabular}

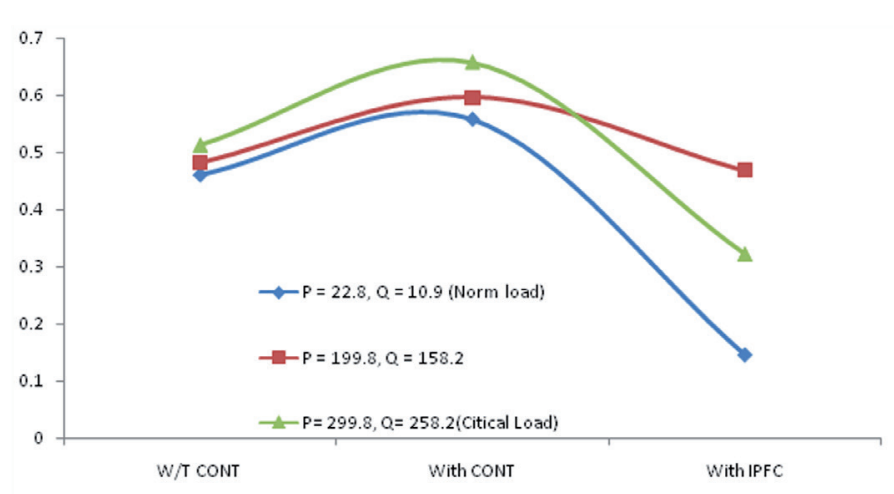

Fig. 8 LUF, FVSI and CSI values for line 3-4 for critical loading without contingency, with contingency and with optimal placement of IPFC

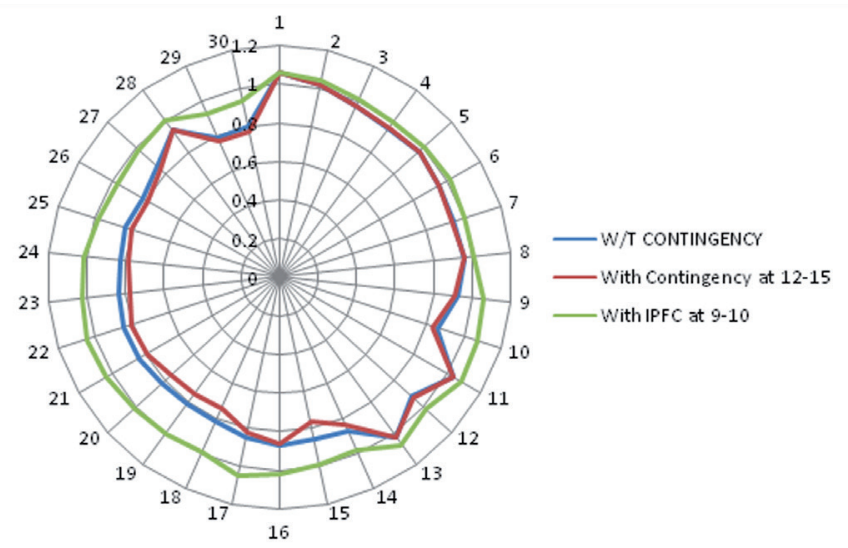

Fig. 9 Voltage Profile without contingency, with contingency and with optimal placement of IPFC

\section{References}

[1] Amjady, N., Esmaili, M. "Application of a New Sensitivity Analysis Framework for Voltage Contingency Ranking." IEEE Transactions On Power Systems. 20 (2). pp. 973-983. 2005. DOI: 10.1109/tpwrs.2005.846088

[2] Donde, V., López, V., Lesieutre, B., Pinar, A., Yang, C., Meza, J. "Severe Multiple Contingency Screening in Electric Power Systems." IEEE Transactions On Power Systems. 23 (2). pp. 406-417. 2008.

DOI: $10.1109 /$ tpwrs.2008.919243

[3] Wan, H.B., Ekwue, A. O. "Artificial neural network based contingency ranking method for voltage collapse." Electrical Power and Energy Systems. 22 (5). pp. 349-354. 2000. DOI: 10.1016/s0142-0615(99)00065-4 
[4] Gasperic, S., Mihalic, R. "Analysis of Voltage Stability in Electric Power System with UPFC." Periodica Polytechnica Electrical Engineering and Computer Science. 59 (3). pp. 94-98. 2015. DOI: 10.3311/ppee.8604

[5] Krishnan, V., McCalley, J. D. "Contingency assessment under uncertainty for voltage collapse and its application in risk based contingency ranking." Electrical Power and Energy Systems. 43 (1). pp. 1025-1033. 2012. DOI: 10.1016/j.ijepes.2012.05.065

[6] Visakha, K., Thukaram, D., Jenkins, L. "Application of UPFC for system security improvement under normal and network contingencies." Electric Power Systems Research. 70 (1). pp. 46-55. 2004.

DOI: 10.1016/j.epsr.2003.11.011

[7] Jayasankara, V., Kamaraj N., Vanaja, N. "Estimation of voltage stability index for power system employing artificial neural network technique and TCSC placement." Neurocomputing. 73 (16-18). pp. 3005-3011. 2010. DOI: 10.1016/j.neucom.2010.07.006

[8] Shaheen, H. I., Rashed, G. I., Cheng, S. J. "Application and comparison of computational intelligence techniques for ptimal location and parameter setting of UPFC." Engineering Applications of Artificial Intelligence. 23 (2). pp. 203-216. 2010. DOI: 10.1016/j.engappai.2009.12.002

[9] Shaheen, H. I., Rashed, G. I., Cheng, S. J. "Optimal location and parameter setting of UPFC for enhancing power system security based on Differential Evolution algorithm." Electrical Power and Energy Systems. 33 (1). pp. 94-105. 2011. DOI: 10.1016/j.ijepes.2010.06.023

[10] Tiwari, A. "Optimal Allocation of Dynamic VAR Support Using Mixed Integer Dynamic Optimization." IEEE Transactions On Power Systems. 26 (1). pp. 305-314. 2011. DOI: 10.1109/tpwrs.2010.2051342
[11] Varshney, S., Srivastava, L., Pandit, M. "Optimal location and sizing of STATCOM for Voltage Security Enhancement using PSO-TVAC." In: International Conference on Power and Energy Systems. pp. 1-6. 22-24. Dec. 2011. DOI: 10.1109/icpes.2011.6156646

[12] Lashkar Ara, A., Aghaei, J., Alaleh, M., Barati, H. "Contingency-based optimal placement of Optimal Unified Power Flow Controller (OUPFC) in electrical energy transmission systems. Scientia Iranica. 20 (3). pp. 778-785. 2013.

[13] Moazzami, M., Hooshmand, R. A., Khodabakhshian, A., Yazdanpanah, M. "Blackout Prevention in Power System Using Flexible AC Transmission System Devices and Combined Corrective Actions." Electric Power Components and Systems. 41 (15). pp. 1433-1455. 2013. DOI: $10.1080 / 15325008.2013 .830655$

[14] Ushasurendra, S., Parathasarthy, S. S. "Congestion managerment in deregulated power sector using fuzzy based optimal location for series flexible alternative current transmission system (FACTS) device." Journal of Electrical and Electronics System Research. 4 (1). pp. 12- 20. 2012. DOI: $10.5897 /$ jeeer 11.143

[15] Ratniyomchai, T., Kulworawanichpong, T. "Evaluation of voltage stability indices by using Monte Carlo simulation." In: Proceedings of the 4th IASME / WSEAS International Conference on Energy \& Environment (EE'09). pp. 297-302. 2009.

[16] Zhang, X. P. "Modeling of the interline power flow controller and the generalized unified power flow controller in Newton power flow." Generation, Transmission and Distribution, IEE Proceedings. 150 (3). pp. 268-274. 2003. DOI: 10.1049/ip-gtd:20030093 